\title{
O DISCURSO FUNDADOR DAS MÍDIAS LEGISLATIVAS DA CÂMARA DOS DEPUTADOS
}

\section{THE FOUNDER SPEECH OF THE BRAZILIAN CHAMBER OF DEPUTIES NEWSMEDIA}

\author{
Antonio Teixeira de Barros \\ Cristiane Brum Bernardes \\ Malena Rehbein Rodrigues*
}

Resumo: Analisa os aspectos políticos do discurso fundador das mídias legislativas da Câmara dos Deputados. Tal discurso compreende os argumentos e justificativas dos responsáveis pela criação, gestão e produção de conteúdos desses veículos e contempla três aspectos: (1) justificativa baseada no princípio constitucional da publicidade; (2) contraposição à agenda negativa da mídia privada sobre o Poder Legislativo; (3) defesa institucional dos veículos legislativos, especialmente política editorial e estratégias de divulgação. A metodologia utilizada consiste na combinação de pesquisa bibliográfica e documental com análise de discurso. Conclui que o sistema de comunicação social informação prioriza uma agenda informativa diferenciada, com enfoques e enquadramentos que não são contemplados pelos veículos privados, ao mesmo tempo que é centrado na difusão de informações jornalísticas, ou seja, o mesmo modelo que impera no setor privado.

Palavras-chaves: Divulgação legislativa; Mídias legislativas; Câmara dos Deputados.

\begin{abstract}
This paper analyzes political aspects of the founder speech of the Brazilian Chamber of Deputies news media. Such speech includes the arguments and justifications of those responsible for the creation, management and content production of these vehicles and includes

\footnotetext{
*Antonio Teixeira de Barros, pós-doutor na área de Informação Ambiental realizado na Universidade Fernando Pessoa (Portugal) e doutor em Sociologia pela Universidade de Brasília (1999). Atualmente é docente e pesquisador do Programa de Mestrado em Poder Legislativo da Câmara dos Deputados (antonio.barros@ camara.leg.br). Cristiane Brum Bernardes, doutora em Ciência Política (2010) pelo Instituto de Estudos Sociais e Políticos (IESP) da Universidade Estadual do Rio de Janeiro (UERJ), mestra em Comunicação e Informação (2004) pela Universidade Federal do Rio Grande do Sul (UFRGS). Atualmente é docente do Mestrado Profissional em Poder Legislativo da Câmara dos Deputados (cristiane.bernardes@ camara.leg.br). Malena Rehbein Rodrigues, doutora em Ciência Política (2011) pelo Instituto de Estudos Sociais e Políticos (IESP) da Universidade Estadual do Rio de Janeiro (UERJ), mestra em Relações Internacionais e Teoria Política Contemporânea pela Universidade de Westminster (Inglaterra, 2003), mestra em Comunicação pela Universidade de Brasília (1997) e graduada em Comunicação Social habilitação Jornalismo - pela Universidade de Brasília (1994). Atualmente é analista legislativo da Câmara dos Deputados, onde trabalha como jornalista e docente do Programa de Mestrado em Poder Legislativo da Câmara dos Deputados (malena.rodrigues@camara.leg.br).
} 
three aspects: (1) justification based on the constitutional principle of publicity; (2) opposition to the negative agenda of private media on the Legislative Branch; (3) institutional defense of legislative vehicles, especially editorial policy and outreach strategies. The methodology used is the combination of literature review and documentary research with speech analysis. It concludes that the information system prioritizes a different news agenda, with approaches and frameworks that are not covered by private vehicle, while it is centered on the dissemination of news information, i.e., the same model that prevails in the private sector.

Keywords: Legislative disclosure; Legislative media; Chamber of Deputies.

\section{Introdução}

A divulgação das atividades do Parlamento tornou-se uma necessidade política para as democracias representativas, uma vez que a relação entre representantes e representados passou a ser mediada pelas tecnologias de informação e pelos modernos recursos de divulgação. A história mostra que a política é construída a partir de interações, ideia recorrente entre os expoentes das Ciências Sociais. Durkheim (2002), por exemplo, ao discorrer sobre as formas de Estado e a democracia, destaca que o Parlamento é um mediador das relações entre Estado e sociedade, ao mesmo tempo que salienta a interação entre os eleitores e seus representantes como essencial para evitar a formação de um estado anômico. De forma similar, Weber (1999) ressalta o papel do parlamento como órgão do Estado e agente de publicidade da política. $\mathrm{O}$ principal obstáculo para o Parlamento cumprir essa missão, segundo a leitura weberiana, é o que ele denomina de política negativa, ou seja, uma agenda focada nos trâmites internos do processo legislativo, sem interesse para os eleitores e a sociedade, como a apreciação de requerimentos, a oitiva de autoridades burocráticas, a realização de reuniões e eventos protocolares, a discussão de projetos sobre datas comemorativas, a apresentação de emendas e a obstrução à votação de determinados projetos de interesse do Poder Executivo, como forma de barganha política.

Com base em tal perspectiva, este texto desenvolve uma análise a partir da seguinte questão: quais os fundamentos do discurso fundador desse sistema de divulgação?

A discussão é orientada pelo argumento de que, diante do cenário dominado pela falta de confiança dos cidadãos nas instituições políticas e nos próprios políticos (MOISÉS, 2010) especialmente no caso do Legislativo brasileiro - , a divulgação das atividades legislativas pela Câmara dos Deputados tem a finalidade de servir como antídoto à desconfiança e contra-agenda ao que é veiculado pela mídia tradicional, ou seja, como fonte alternativa de informação, cuja disponibilidade consiste em um dos pré-requisitos da democracia, segundo Dahl (1989).

$\mathrm{O}$ estudo foi realizado com base em três técnicas de pesquisa inter-relacionadas e complementares, formando uma triangulação metodológica, conforme propõe Goldenberg (2001). A primeira, a pesquisa documental, compreendeu o exame de documentos 
institucionais, sob a perspectiva da coleta de dados objetivos e também de avaliação qualitativa, com objetivo de contextualizar o aparato burocrático de divulgação legislativa. Nessa etapa, o propósito foi compilar e sistematizar as informações documentais, sob uma perspectiva qualitativa, entendendo os documentos institucionais como arquivos sociais de uma memória política e institucional que se organizou na forma de discurso. Trata-se de abordagem segundo a qual o discurso fundador vem a ser uma formação discursiva que funciona como referência primária para a compreensão da gênese do sistema de divulgação em foco, com o auxílio de conceitos oriundos do campo da análise de discurso (ORLANDI, 2001, 2007; KARVAT, 2005).

Em termos operacionais, a pesquisa foi realizada no período de 2005 a 2010, iniciando com um levantamento exploratório sobre o tipo de informação divulgada, os gêneros discursivos e os conceitos básicos que estavam implícitos nos documentos institucionais de uso interno, tais como 'interesse público', 'transparência', 'jornalismo público', entre outros. ${ }^{1} \mathrm{~A}$ partir desse levantamento surgiu o projeto de analisar especificamente os elementos que conformam o discurso fundador do aparato de divulgação legislativa, com o propósito de caracterizar os elementos discursivos que sustentam e justificam a política institucional e as práticas de divulgação das atividades legislativas. Essa etapa específica foi realizada durante o ano de 2011, com base nos dados anteriormente coletados, no exame da bibliografia estudada e no aprofundamento da pesquisa documental focada na identificação e sistematização dos componentes, abordagens e dimensões do discurso fundador do aparato de divulgação da Câmara dos Deputados, com o auxílio da análise do discurso, conforme já explicitado.

O corpus da pesquisa é formado pelos documentos mais relevantes, em termos de definição de atribuições, estabelecimento das diretrizes e estratégias de divulgação, estilo de redação e organização das rotinas e dinâmicas de produção dos veículos e dos profissionais. Em ordem cronológica, temos os seguintes documentos: (1) Resolução no 20, de 1971, que criou a Assessoria de Relações Públicas e Divulgação (Adirp); (2) Ato da Mesa Diretora da Câmara dos Deputados no 96, de1998, que criou a Secretaria de Comunicação Social da Câmara dos Deputados (Secom), em substituição à Adirp; (3) Manual de Redação da Secom, publicado em 2004; (4) Relatórios dos seminários anuais da Secom, realizados no período de 2003 a 2011; (5) Atas e relatórios dos seminários internos promovidos para discutir e redefinir as políticas e diretrizes de divulgação legislativa.

Essa análise apresenta ainda nuances de observação participante, resultante do acompanhamento diário das atividades de divulgação pelos autores no período de seis anos (2005 a 2011), o que envolveu ainda entrevistas e conversas informais com gestores e integrantes das diferentes equipes de trabalho no âmbito da Secretaria de Comunicação Social da Câmara dos Deputados. Como se trata de uma pesquisa documental de cunho discursivo e o

\footnotetext{
${ }^{1}$ Para detalhes, consultar: Barros e Bernardes, 2009.
} 
discurso é uma prática social e politicamente condicionada, antes do exame dos elementos que compõem o discurso fundador são apresentadas informações contextuais consideradas relevantes para a compreensão do escopo analítico da pesquisa. Trata-se de um breve levantamento sobre as políticas e práticas de comunicação e informação no Brasil, no âmbito institucional, com destaque para o Poder Legislativo.

\section{Contextualização do aparato de divulgação da Câmara dos Deputados}

A criação do aparato de divulgação do Parlamento brasileiro, apesar de resultar de processo político e burocrático recente, deve ser examinado à luz do contexto histórico. Tal empreitada não dispensa uma rápida síntese da evolução política dessa estrutura de comunicação, cujos marcos foram a fundação da TV Assembleia de Minas Gerais em 1995 e da TV Senado em 1996, a partir do espaço aberto com a legislação da TV por assinatura (Lei $n^{\circ}$ 8.977, de 1995). Com a abertura política propiciada pela Constituição de 1988, as duas casas legislativas do Congresso Nacional seguiram o caminho de outros órgãos legislativos e investiram na comunicação eletrônica com veículos próprios de televisão e de rádio. Ainda na década de 1990, foram criados os serviços de atendimento telefônico gratuito à população (Alô Senado e Disque-Câmara), duas emissoras de rádio (Rádio Senado e Rádio Câmara) e duas agências de notícias online (Agência Senado e Agência Câmara).

As mídias institucionais devem ser entendidas como resultantes do processo de redefinição dos canais de informação que já existiam. Assim, o atual aparato burocrático de divulgação do Parlamento e das demais instituições tem sua origem mais remota na tradição do rádio educativo, sistema estratégico utilizado pelo Estado brasileiro para transmitir e difundir conteúdos instrucionais à população a partir da década de $1930 .^{2}$ Após sua consolidação no Brasil, com a emergência da televisão, o sistema de rádio educativo serviu de matriz e de paradigma para o desenvolvimento da TV educativa no final da década de 1960. Essa, por sua vez, constituiu a base para o surgimento das emissoras de TV institucionais ${ }^{3}$, a partir das possibilidades admitidas pela legislação da TV por assinatura. Cabe ressaltar, por fim, que a disseminação das emissoras de TV institucionais serviu de mote para a criação das emissoras de rádio pelos diferentes poderes. Em suma, a tendência inverteu-se: se no passado a TV educativa surgiu na esteira do rádio educativo, na década de 1990 as emissoras de rádio institucionais foram criadas no lastro dos canais de TV, como estratégias de reforço das iniciativas dos poderes públicos de manter canais diretos de comunicação com a sociedade, sem a interferência dos filtros dos veículos privados.

Entretanto, é oportuno ressalvar que as iniciativas governamentais na área de comunicação no Brasil não são recentes, especialmente no que se refere ao Poder Executivo.

\footnotetext{
${ }^{2}$ Para um histórico pormenorizado ver Pimentel, 2004.

${ }^{3}$ Para mais detalhes ver: Barros, Bernardes e Lima, 2010.
} 
Desde a década de 1930, o governo federal utilizava-se de programas radiofônicos para divulgação institucional e propaganda política, sem mediações de terceiros. O exemplo mais conhecido é 'A Voz do Brasil'4, criada em 1935 para noticiar os feitos governamentais. Em 1939, foi criado o Departamento de Imprensa e Propaganda (DIP), principal iniciativa do presidente Getúlio Vargas em comunicação. Com o fim da era Vargas, em 1945, o programa passou à jurisdição da antiga Agência Nacional, órgão do Departamento Nacional de Informações, que substituiu o DIP.

Assim como no Poder Executivo, o Poder Legislativo iniciou seu projeto de comunicação por meio do rádio. Em 1952, algumas câmaras municipais contratavam rádios locais para transmissão de suas sessões. Contudo, o legislativo federal só chegou às rádios dez anos mais tarde, em 1962, após a transferência da capital federal para Brasília. Nessa época, o programa 'A Hora do Brasil' passou a chamar-se 'A Voz do Brasil' e a dividir o tempo de transmissão diária com os poderes Legislativo e Judiciário (ADGHIRNI, 2006). Os núcleos de rádio do Senado Federal e da Câmara dos Deputados surgem com as respectivas equipes responsáveis pela produção de 'A Voz do Brasil', que alimentavam por meio de um banco de radiorreportagens 400 emissoras em todo o país.

\section{0 discurso fundador das mídias legislativas}

Nessa ordem de ideias, o discurso fundador ${ }^{5}$ do aparato burocrático de divulgação da Câmara dos Deputados, objeto desta análise, é composto pelos argumentos e justificativas dos responsáveis pela criação, gestão e produção de conteúdos dos veículos de informação. Trata-se de uma modalidade de discurso identitário ainda em formação, uma vez que o sistema, em sua configuração atual, foi criado no final da década de 1990 e passou a recrutar profissionais desde então. Antes havia apenas alguns mecanismos de atendimento à imprensa e de comunicação institucional e relações públicas, conforme foi apresentado anteriormente.

Uma das características do discurso desse grupo é a crítica em relação à cobertura do Poder Legislativo pela mídia privada. Destacam-se nesse processo discursivo os profissionais que integraram a comunidade de origem e participaram da cena fundante que resultou no atual sistema de comunicação da Câmara dos Deputados. Esses agentes burocráticos produzem um discurso racional que tenta construir e reforçar os traços de uma identidade profissional em formação, cuja estratégia de afirmação consiste, basicamente, na contraposição às práticas da mídia privada, embora os profissionais recrutados, via concurso público, sejam oriundos do setor privado. Afinal, o Brasil não possui escolas de formação para comunicadores do setor público, e os currículos universitários dos cursos de jornalismo são quase inteiramente voltados

\footnotetext{
${ }^{4}$ Inicialmente o nome era 'Hora do Brasil'.

${ }^{5}$ Recorremos aqui à terminologia de Orlandi (1990), como explicitado anteriormente.
} 
para o trabalho nas redações de jornais, TVs, rádios e assessorias de imprensa das empresas de comunicação do setor privado. Uma vez que a comunicação de uma instituição pública apresenta objetivos e funções distintas de uma empresa comercial de mídia, é cabível o questionamento acerca da organização de um sistema público de informação mediante a contratação de profissionais recrutados do mercado, sem um treinamento intensivo para a atuação no âmbito público. Há, portanto, uma situação emblemática para ser estudada e que exemplifica, em boa medida, uma mudança no cenário das práticas de comunicação adotadas no País.

A primeira turma de jornalistas concursados ingressou na Câmara dos Deputados no segundo semestre de 1998, mediante o aproveitamento do excedente de um concurso promovido pelo Senado, exclusivamente para a área de comunicação, em 1997. Aquele já era o segundo concurso para profissionais da área no Senado, mas ocorria dez anos após o primeiro. Foram convocados para a Câmara dos Deputados profissionais das áreas de rádio, TV e imprensa escrita. A maioria, como já foi ressaltado, oriunda do setor privado. De acordo com a cultura jornalística da época, participar de um concurso público para trabalhar em veículos institucionais seria atitude de profissionais cansados das rotinas das mídias privadas, em que ainda se encontravam rescaldos da visão do jornalista como missionário, que deveria viver para o trabalho, para a notícia ${ }^{6}$ e que, portanto, não tinha tempo para outras coisas, uma vez que trabalhava até aos domingos e feriados. Aqueles que estavam ingressando no Legislativo, em razão disso, eram também vistos como os que estavam basicamente interessados em ganhar bem ainda que fosse "mudando de lado", ou seja, tornando-se "chapa branca", pois naquela época era para isso que se pensava que serviam os veículos institucionais. De fato, levando em conta a forma como era montada a estrutura, tal impressão era facilmente justificável. O secretário de Comunicação acumulava o cargo de assessor de imprensa da Casa e do presidente, de cunho mais político, o que propiciava uma mistura completa entre perspectivas institucionais e políticas ou pessoais do presidente da Casa. Tal configuração só mudou em 2002, quando o novo secretário de Comunicação deixou de ser assessor do presidente da instituição. Entretanto, até hoje a Secretaria de Comunicação é um dos poucos órgãos da Casa que está submetido diretamente à Presidência da Câmara — e não à Diretoria-Geral, como a maioria —, revelando a visão estratégica e política que adotada para o setor.

Inicialmente, também, os repórteres recém-nomeados não tinham permissão para fazer qualquer pergunta aos deputados, em contrariedade a princípio básico do jornalismo. Eram autorizados somente a coletar falas pronunciadas espontaneamente pelos parlamentares nas reuniões das comissões, no Plenário ou durante entrevistas para os demais veículos. No máximo era possível tirar dúvidas ou pedir esclarecimentos sobre as declarações. Tal funcionamento

\footnotetext{
${ }^{6}$ Tal cultura sempre trouxe muito glamour para a profissão.
} 
também começou a mudar no início do novo milênio.

Especialmente em razão dos fatores apontados acima, os profissionais que entraram queriam mostrar que o jornalismo legislativo poderia tornar-se profissional. Essa disposição entrou imediatamente em choque com os funcionários da Câmara que já trabalhavam na área de comunicação, muitos deles advindos de outras áreas e admitidos na Casa sem passar por concurso público. Para estes, os novos estavam entrando para lhes tirar o lugar e, por isso, era preciso colocá-los "sob comando". Tal conflito permaneceu intenso por pelo menos uma década e ainda não se resolveu por completo. Mesmo que tenham se influenciado mutuamente ao logo do tempo, os dois grupos adotam perspectivas distintas, quais sejam: trabalha-se prioritariamente para os deputados, segundo os antigos; trabalha-se prioritariamente para a sociedade, para os mais novos. Durante os primeiros anos, os jornalistas mais novos também não eram respeitados pelos de mercado, mesmo no convívio diário de cobertura das atividades da Casa. Isso começou a mudar somente depois que os profissionais de fora começaram a se servir das notícias preparadas pela Câmara para abastecer os veículos privados, ou seja, após um trabalho contínuo de credibilidade como esforço dos veículos institucionais. Para isso, obviamente utilizaram-se os critérios jornalísticos de mercado. Ou seja, não só porque os novatos eram advindos do mercado, como já se mencionou, mas também para obter aceitação e legitimidade perante a mídia privada é que os critérios externos foram e em grande medida ainda são usados pelos veículos institucionais. No início dos anos 2000 é que as discussões sobre comunicação pública e missão dos veículos da Câmara passaram a tomar maior corpo, mas avançam em processo lento, ainda que dialético, até hoje.

A seguir, apresentamos os componentes básicos de discurso fundador das mídias da Câmara dos Deputados. De forma resumida, o discurso coletivo analisado neste trabalho é formado por três vertentes principais: (1) a justificativa baseada no princípio constitucional da publicidade; (2) a contraposição à agenda negativa da mídia privada com respeito ao Poder Legislativo; (3) e a defesa institucional dos veículos legislativos, especialmente no que se refere à política editorial e às estratégias de divulgação.

\section{Princípio constitucional da publicidade}

Os agentes burocráticos do discurso fundador argumentam que as ações de comunicação do Poder Legislativo resultaram de estratégias para aperfeiçoar os mecanismos racionais de relacionamento entre o Parlamento e a sociedade e também para ampliar a transparência da instituição. Dessa forma, ao institucionalizar um sistema próprio de informação, a Câmara dos Deputados baseou-se no princípio constitucional de que o cidadão tem direito à publicidade dos atos, decisões e atividades legislativas. Trata-se, portanto, do princípio constitucional integrante dos sistemas racionais de governo representativos.

Na pesquisa documental realizada, observa-se que a Resolução $n^{\circ} 20$, de 1971, da 
Câmara dos Deputados, definiu as atribuições da Adirp nos seguintes termos:

Art. $5^{\circ}$ À Assessoria de Divulgação e Relações Públicas compete informar e esclarecer a opinião pública a respeito das atividades da Câmara dos Deputados, utilizando, para isso, os veículos de divulgação e as técnicas de Relações Públicas e assessorar o Presidente em questões de cerimonial (grifos acrescentados).

Percebe-se, assim, pelos termos destacados, que já em 1971 o propósito extrapolava o princípio constitucional da publicidade, uma vez que, além de informar, já se previa o uso de técnicas de relações públicas para o esclarecimento da opinião pública.

O Manual de Redação da Secom, publicado em 2004, retoma o eixo do argumento constitucional, ao afirmar que "os veículos de informação da Câmara devem preservar e aperfeiçoar sua missão básica: serem instrumentos à disposição da sociedade brasileira, para que esta tenha acesso a informações objetivas, isentas e apartidárias sobre os trabalhos legislativos" (MALAVAZI, 2004, p. 20 - grifos acrescentados).

Os dois documentos revelam formações discursivas distintas e se baseiam em conceitos distintos de publicidade. No primeiro caso, o foco da divulgação é o emprego de técnicas de esclarecimento da população, de formação da opinião pública, mediante instrumentos de relações públicas, o que se explica pelo prestígio de tal atividade naquele contexto social e político, ou seja, durante a ditadura militar. Trata-se de uma visão que mistura informação e marketing, com vistas à obtenção de uma boa imagem para o Legislativo e que ainda se encontra presente em vários momentos, a depender, por exemplo, do que pretende o presidente da Casa, pois, a Secretaria de Comunicação está subordinada diretamente ao titular do cargo de presidente da instituição.

O momento subsequente reflete a visão política e profissional da redemocratização, quando o jornalismo tornou-se a atividade de maior prestígio em termos de publicidade e visibilidade da política. Aqui está representada a visão que considera o discurso da cidadania, ou seja, informar para educar, ampliar a participação política e possibilitar a fiscalização. Tratase, em suma, do discurso tradicional de responsabilidade social, uma espécie de discurso de autolegitimação do jornalismo, que vige desde as revoluções burguesas do século XVIII e afirma uma vinculação à sociedade civil, cujos interesses o jornalismo representaria, ao mesmo tempo que seria independente e fiscalizador da esfera política, em nome desse interesse público (TRAQUINA, 2002, p. 74; 75) ${ }^{7}$.

O que se percebe no discurso expresso pela "voz da burocracia", ou seja, pelos documentos analisados, é que há duas ordens de racionalidade que coexistem e se

\footnotetext{
${ }^{7}$ Do ponto de vista da história do jornalismo, dois momentos marcaram a ascensão desses paradigmas: o "Novo Jornalismo", em meados do século XIX, cuja ideia principal era separar fatos e opiniões; e no século XX (anos 1920 e 1930), com o surgimento do conceito de objetividade jornalística, nos Estados Unidos (TRAQUINA, 1993, p. 167168).
} 
complementam, ou seja, uma corresponde às instâncias burocráticas de divulgação e relações públicas e a outra incorpora elementos da racionalidade jornalística, que se manifestam principalmente pelo capital da objetividade. Trata-se, portanto, de uma estratégia de agregar aos veículos de divulgação do Parlamento o capital simbólico da credibilidade inerente ao jornalismo. Provavelmente por isso, a organização burocrática do sistema é construída com tanta ênfase na nomenclatura e nos expedientes do jornalismo (veículos legislativos e mídias legislativas, por exemplo).

A perspectiva da publicidade como agente de visibilidade da política passa a embasar os pressupostos discursivos dos documentos que seriam produzidos pela instituição para normatizar as atividades de seu aparato de divulgação, inclusive com a contratação de jornalistas profissionais e o uso de nomenclaturas próprias da profissão, tais como mídias legislativas ou veículos legislativos. O fato é que o argumento da publicidade dos atos das instituições políticas foi redefinido e transcendeu o sentido inicial, alinhando-se com o sentido republicano de publicidade desenvolvido desde o início das formulações da Teoria Política sobre a República, conforme argumenta Guizot (2008), o que significa transparência nas decisões governamentais para que os representados possam se envolver nos assuntos públicos. Tal perspectiva adquiriu legitimidade inclusive no campo dos estudos políticos de maior projeção no meio acadêmico, a exemplo de Bobbio (2005, p. 28), segundo o qual "o poder político é o poder público (...) mesmo quando não é público, não age em público, esconde-se do público, não é controlado pelo público.” Ainda segundo o autor, a República diferencia-se dos regimes autoritários ou absolutistas exatamente porque há um controle público do poder e a livre formação de uma opinião pública. O caráter público do governo representativo - ou, nos termos contemporâneos da discussão política, a transparência das decisões governamentais - é ressaltado na passagem em que o autor argumenta que, nos casos em que a assembleia é a reunião dos representantes do povo, quando então a decisão seria pública apenas para estes e não para todo o povo, as reuniões da assembleia devem ser abertas ao público, de modo que qualquer cidadão a elas possa ter acesso (BOBBIO, 2005).

Para cumprir a obrigatoriedade da publicidade das ações e, ao mesmo tempo, garantir uma divulgação favorável de informações, as instituições públicas desenvolveram uma série de estratégias, que incluem desde a tradicional assessoria de imprensa até os novos veículos de mídia institucionais, passando por campanhas de publicidade institucional e promoção de eventos, entre outras, mas sempre em consonância com os princípios democráticos e republicanos.

Nessa perspectiva, o primeiro argumento constitutivo do discurso fundador recorre a elementos consensuais tanto do ponto de vista legal como político, ao privilegiar o princípio constitucional da publicidade e a consequente visibilidade e transparência dos atos do Poder Legislativo. Por constituir uma razoável justificativa política, tal argumento dá legitimidade às 
novas mídias criadas pelo Poder Legislativo, as quais são responsáveis pela comunicação de suas ações para a sociedade. Desse modo, os veículos de mídia da Câmara cumprem uma função essencial para o próprio regime democrático: a transparência das decisões legislativas necessária para a legitimidade social do sistema político institucional representado pelo Parlamento brasileiro. Trata-se, em suma, de uma adesão à lógica racional republicana.

\section{Deficiências da mídia privada}

A criação dos veículos informativos da Câmara baseia-se, ainda, na constatação de que é dever da instituição complementar a atuação da imprensa comercial na publicização das atividades parlamentares, a fim de compensar o que foi caracterizado como as deficiências da mídia privada. A iniciativa teve como base o diagnóstico negativo da imagem das instituições legislativas, o papel dos veículos da mídia comercial nesse quadro e a possibilidade de alterá-lo. Assim, o possível efeito negativo da cobertura da mídia para a imagem do Parlamento é outro componente importante do discurso fundador e está relacionado ao que foi posto no item anterior com relação à mistura entre jornalismo, relações públicas e marketing.

Conforme destaca Malavazi (2004, p. 23) no próprio Manual de Redação da Secom, os veículos são instrumentos essenciais para “[...] que haja maior correspondência entre a imagem pública da Câmara e a realidade da atividade legislativa, sem as distorções derivadas de estereótipos e preconceitos." Esse trecho do documento sintetiza o diagnóstico realizado pela Instituição acerca da divulgação realizada pela mídia comercial e apresenta os princípios normativos da divulgação legislativa em contraposição à mídia comercial. De maneira similar, o documento reforça o discurso de que a cobertura da mídia privada é parcial e seletivamente prejudicial à imagem do Parlamento e estabelece como princípio editorial do sistema institucional a divulgação das mais variadas atividades legislativas, incluindo as reuniões das comissões técnicas, “[...] que recebem escassa cobertura da mídia em geral, não obstante sejam uma das instâncias mais importantes de produção da Casa" (MALAVAZI, 2004, p. 24). O manual acabou servindo também como uma barreira a pressões de uso pessoal e político das mídias da Câmara, ou seja, os deputados que quisessem usar os veículos pessoalmente teriam também de respeitar os preceitos do documento oficial de comunicação da Casa.

De modo geral, a existência dos serviços de divulgação legislativa é justificada pelo discurso institucional dos próprios jornalistas contratados pela Câmara dos Deputados de que as práticas e as rotinas da mídia comercial concorrem para um tratamento episódico e fragmentado dos assuntos que poderiam favorecer o exercício da cidadania e da democracia. No caso específico da cobertura sobre o Legislativo, o discurso institucional é que a agenda, os critérios de seleção, os valores-notícia, o enquadramento e a tematização dos jornalistas e das empresas de mídia contribuem para reforçar uma imagem negativa da instituição que, longe de oferecer uma crítica que incentive a participação no debate público, parece contribuir para esvaziá-lo 
(RODRIGUES, 2011).

Os agentes desse discurso argumentam ainda que o conhecimento da população sobre o Poder Legislativo passa, necessariamente, pelos filtros da cultura dos jornalistas que cobrem o Congresso Nacional, dos editores que finalizam as matérias e, por extensão, dos próprios veículos, que costumam desqualificar a instituição e seu papel na democracia. Tal discurso pressupõe uma visão dos jornalistas dos grandes veículos de mídia por si próprios e pelo público como os representantes da população perante o Estado, como mediadores do conflito e "[...] responsáveis pela transparência da administração pública e pela denúncia e vigilância do poder político" (ALDÉ, 2004, p.178). De certa maneira, é natural que isso ocorra no âmbito da cultura de cobertura do Legislativo, em que jornalistas e fontes convivem e discutem suas matérias diariamente, criando relações de reciprocidade, enquanto os públicos e suas possíveis cobranças estão bem mais longe.

Na perspectiva do discurso fundador aqui analisado, a desinformação do público sobre o Poder Legislativo compromete a legitimidade da representação popular e do mandato parlamentar, além de prejudicar o diálogo entre representantes e representados. Afinal, a visibilidade é da natureza do poder, como destaca Thompson (1995). Os parlamentares são eleitos pelo povo. Como eles podem, então, representar seus eleitores, se a população não é devidamente informada sobre suas atividades rotineiras, como pronunciamentos, projetos de leis, participação em comissões? Sem informação sobre as atividades parlamentares, como exigir que a população seja vigilante e faça cobranças continuadas sobre as atividades daqueles que foram eleitos para defender seus interesses? Esses são alguns dos questionamentos frequentemente repetidos e reiterados pelos gestores das mídias legislativas, como tentativa de tornar o debate racional. Afinal, como ressaltam as teorias sobre agendamento noticioso, quanto mais proximidade alguém possui em relação a determinado tema, mais quer saber sobre ele e menos agendável se torna em relação a ele.

Tais questionamentos encontram respaldo na análise de autores como Entman (1989) e Beetham (2005). O primeiro, por exemplo, acredita que o atual sistema de mídia não encoraja a verdadeira accountability, mas apenas a "retórica da moda" (ENTMAN, 1989, p. 20), uma vez que os atores políticos são estimulados a agir de acordo com os valores jornalísticos e não para o alcance das políticas públicas necessárias. O jornalismo comercial não consegue seguir as condições básicas para a accountability dos governos, porque simplesmente sua rotina não contribui naturalmente para isso (RODRIGUES, 2011). Para o autor, entre essas condições para o controle público estão: a contextualização histórica dos fatos relatados, a diversidade de perspectivas e as conexões explícitas entre os fatos e as autoridades responsáveis.

Beetham (2005) alerta que o jornalismo no modelo privado pode atrapalhar a conquista dos direitos individuais. A concentração da propriedade dos veículos de comunicação é um dos problemas principais das atuais sociedades, segundo ele. A ausência de pluralismo nas visões 
presentes na mídia e a falta de informação pública para os cidadãos são obstáculos ao cumprimento do direito individual de liberdade de expressão. Tais situações são exacerbadas em casos de monopólio ou oligopólio dos meios de comunicação, sejam estatais ou privados.

Nesse debate, é oportuno lembrar o tema da liberdade de expressão, outro aspecto recorrente no escopo da discussão que compara a atuação da mídia privada com a performance das mídias legislativas. Para Ferry (2002), a concepção convencional de liberdade de expressão, da forma como é praticada pelos veículos comerciais, chega até a ser maléfica à cidadania, pois institucionaliza e legitima o monopólio privado da crítica e da opinião, com base no poder discricionário de uma categoria profissional (os jornalistas) que não tem legitimidade política para representar a opinião dos cidadãos. Essa categoria, a seu ver, monopoliza ainda a prerrogativa de definir a agenda pública, com a consequente escolha do enquadramento temático e ideológico para os debates públicos, que na visão dele não são realmente públicos, já que são delineados pelos jornalistas e pelas empresas de mídia.

Contudo, é oportuno salientar que esse poder discricionário dos jornalistas também está presente nas mídias legislativas, mesmo com os limites dos enquadramentos institucionais. A administração do Parlamento define as linhas gerais da cobertura, mas são os produtores, repórteres e editores que decidem o que será destacado, qual aspecto comporá o núcleo da notícia, como será a manchete, qual foto será escolhida, o que merecerá divulgação prioritária em tempo real, etc. Isso decorre exatamente do modelo de mídia criado pelo Poder Legislativo, focado no formato de jornalismo para a cobertura da agenda do Parlamento.

Por isso, os veículos precisam aqui ser entendidos como instituições políticas. Aplicando o conceito do novo institucionalismo, pode-se dizer que as mídias noticiosas possuem atributos necessários para serem consideradas uma instituição com padrões de comportamento e funcionamento comuns, rotinas e suposições que sobrevivem para além do limite de espaço e tempo e que são vistas como naturais. Mais do que isso, são uma instituição que não só faz parte da política, mas também do ato de governar, e sem a qual os três poderes da República não conseguiriam atuar (COOK, 1998). Não se trata da muito usada definição de imprensa como quarto poder; isso porque os meios de comunicação são propriedade privada, não têm direitos e deveres ou funções constitucionais estabelecidas ainda que sob proteção da lei, nem são investidos de autoridade para tomar decisões a serem acatadas pela sociedade, como os poderes constituídos (COOK, 1998). Recebem patrocínio, anúncios privados. São, portanto, instituições políticas intermediárias, agentes políticos plenos, mais como partidos ou grupos de interesse do que como um dos três poderes constitucionais. Até por isso, muitas vezes os 'media' são apontados como substitutos dos partidos ou, pelo menos, agentes partidários, ao procurar representar, sem mandato, valores e interesses de segmentos da sociedade. Deixam de ser instituições da sociedade civil para ser instituições da sociedade política (RUBIM, 1994).

Apesar de todas as ressalvas e restrições à cobertura da mídia privada sobre o 
Legislativo, é inegável a importância política dos veículos de comunicação de massa, concepção presente nos estudos citados. Há pesquisas que apontam que as regras políticas passam a ter um valor alterado com a crescente influência social dos meios de comunicação sobre o campo político (LIMA, 2001; MIGUEL, 2008; RUBIM, 1994). Sartori (2001) chega a utilizar a expressão "videopolítica" para definir, nas sociedades contemporâneas, o novo poder político da televisão de divulgar um fato e, com essa ação, fazê-lo acontecer. Um tipo de "capital delegado" passa a ser importante para a legitimidade dos atores, ou seja, passam a valer na disputa política características, qualidades e o reconhecimento obtidos em outras atividades, como o campo artístico ou a própria mídia (BOURDIEU, 2006).

Em suma, os responsáveis pela gestão interna das mídias legislativas enfatizam as deficiências da cobertura realizada pela mídia comercial que, ainda que conte com liberdade de expressão, contribui mais para o desgaste da democracia do que para seu aperfeiçoamento, ao se pautar por estereótipos redutores do papel do Parlamento (MIGUEL, 2008). As atividades de informação política empreendidas pelos veículos institucionais do Legislativo pretendem suprir essas deficiências ou, como já indicamos no início deste artigo, fazer parte das fontes alternativas de informação, colocadas por Dahl (1989) como essenciais à democracia.

Como se observa, esse aspecto do discurso fundador das mídias legislativas é centrado numa avaliação negativa das mídias privadas e numa subjacente crítica ao modelo de jornalismo convencional. Contudo, o que se percebe é que o aparato burocrático de comunicação do Poder Legislativo tem como referência os padrões privados, até mesmo pela origem dos profissionais que atuam no sistema, como já mencionamos. Alguns jornalistas do sistema de comunicação da Câmara admitem que há necessidade de desenvolver uma linguagem própria para os veículos da instituição, mas outros afirmam que o jornalismo, tal como exercido nas demais mídias, deve ser o parâmetro essencial para a atividade das mídias legislativas, para que elas adquiram credibilidade.

A discussão sobre o uso dos parâmetros midiáticos convencionais por instituições públicas é recorrente entre os autores que estudam comunicação pública. Libois (2002) aponta que a transposição de pressupostos da mídia privada para os sistemas públicos de informação contribui para reproduzir os problemas na transmissão de informações para os cidadãos. Essa ideia é reforçada por Ferry (2002). A seu ver, ao copiar os padrões da mídia privada, os sistemas públicos de informação reiteram e reproduzem os vícios do mercado, considerados por ele maléficos à cidadania. Ademais, transmite ao público a concepção de que o padrão ideal de comunicação é aquele da mídia comercial, já que deve ser copiado. Com isso, os agentes dos sistemas públicos de comunicação privam os cidadãos de serviços substancial e efetivamente diferenciados de informação, com maior aprofundamento na cobertura, pluralidade de abordagens e de fontes, além da diversidade de agendas. Por outro lado, pode-se considerar a hipótese de opção deliberada pelo padrão comercial como estratégia racional de afirmação do 
sistema burocrático de informação do Poder Legislativo, ou seja, utilizar-se de um modelo que goza da credibilidade da opinião pública serve para dar legitimidade às iniciativas da burocracia informacional. Este seria, na realidade, um primeiro passo, para garantir legitimidade ao processo de aprofundar as informações e diferenciar a linguagem das mídias institucionais.

\section{0 discurso institucional sobre os veículos legislativos}

Acerca da defesa dos veículos legislativos, um dos aspectos consensuais, do ponto de vista dos agentes burocráticos do discurso fundador, é que os sistemas de comunicação mantidos pelo Poder Legislativo contribuem para aumentar as opções de informações relativas ao Parlamento para o cidadão. Um dos pilares racionais dessa justificativa é a defesa do interesse público, associada aos conceitos de comunicação pública, transparência e responsabilidade social da instituição. Segundo o referido manual, o sistema de comunicação da Câmara, "em sintonia com a transparência e o caráter democrático da instituição Câmara dos Deputados, é público porque assume a responsabilidade de emitir, transmitir e receber mensagens da sociedade brasileira, sempre com o sentido de responsabilidade social" (MALAVAZZI, 2004, p.26). Ou seja, mais uma vez encontra-se aqui o discurso de autolegitimação do jornalismo, que já foi citado anteriormente. Ele passa a ser transposto à realidade institucional.

O pressuposto racional, portanto, é o de que se o cidadão estiver interessado, não ficará dependente da mídia privada para se informar sobre o trabalho parlamentar; como se trata das teorias sobre agendamento noticioso, quando mais próximo do tema, mais ele se informará e mais capaz de crítica própria ele será. Os gestores institucionais dos veículos de divulgação legislativa argumentam ainda que a maior disponibilidade de informações, sem os filtros da mídia privada, representa um ganho significativo para a democracia, a representação política e a cidadania. Afinal, complementam, o Parlamento produz um número expressivo de notícias, a partir de dezenas de seminários, audiências públicas e reuniões de comissões que ocorrem simultaneamente e não recebiam atenção da mídia privada antes da existência dos veículos institucionais ou, quando recebiam, era mais por alguma participação de personagem importante do Executivo, que no Legislativo poderia ser mais facilmente abordada (RODRIGUES, 2011). Além disso, ressaltam que até a cobertura do Plenário ficou mais transparente e didática, facilitando a compreensão do cidadão interessado, muito embora a linguagem ainda seja bastante técnica.

Tal concepção encontra respaldo em alguns estudos sobre os veículos de comunicação legislativos, os quais mostram que informações antes não acessíveis ao cidadão hoje estão disponíveis, como resultado da atuação desses veículos (RENAULT, 2004), e passaram também a ser reproduzidas pela mídia externa. Nessa visão, destaca-se a percepção de que o funcionamento de tais veículos introduz modificações significativas no próprio processo de 
produção legislativa (COOK, 1998; RENAULT, 2004; SANTOS, 2005). Essas modificações incluem a maior presença dos parlamentares no Plenário e nas reuniões de comissões, o aumento do tempo dos discursos, a maior quantidade de falas, a contratação de mais profissionais de imprensa e mesmo a simples preocupação com o visual e com a oratória adequada aos meios eletrônicos. Além disso, alguns estudos também apontam que a cobertura dos veículos legislativos "quebrou o monopólio da mídia comercial na definição da agenda pública" (SANTOS, 2005, p. 23) e levou para a casa dos cidadãos informações em tempo real e mais detalhadas sobre o funcionamento do Parlamento (RENAULT, 2004) ${ }^{8}$. Para os parlamentares, principalmente os excluídos da grande mídia, acaba sendo mais fácil conseguir espaço na mídia interna.

São esses pressupostos que norteiam a política editorial e as diretrizes para o funcionamento do sistema de informação da Câmara dos Deputados, ao priorizar critérios racionais como cobertura imparcial e apartidária ou suprapartidária, a fim de oferecer ao cidadão o máximo de informação sobre as atividades legislativas. Os profissionais do sistema afirmam que o trabalho é dirigido à sociedade brasileira e não aos parlamentares e seus públicos vinculados. Entretanto, muitos ressalvam que nem sempre os parlamentares entendem a necessidade de uma política editorial baseada em aspectos institucionais, o que causa conflito entre a concepção dos diretores dessas mídias e as demandas parlamentares, na maioria dos casos, voltadas para a promoção pessoal desses agentes políticos. Enquanto gestores e profissionais priorizam mecanismos racionais e burocráticos expressos nos princípios suprapartidários e pluralistas de divulgação, os parlamentares reivindicam visibilidade para atos e declarações pessoais ou de seu partido. Ao priorizar os mecanismos racionais e burocráticos, os gestores pretendem criar um discurso de resistência a influências pessoais dos parlamentares (BERNARDES, 2013).

Para efeitos de maior impessoalidade e racionalidade na prestação de serviços, a Câmara dos Deputados passou a realizar concursos públicos para reforçar os quadros profissionais a partir da década de 1990, o que pode ser considerado um avanço para consolidar uma cultura interna de profissionalização da cobertura legislativa, de forma apartidária e plural. Afinal, se o jornalista contratado não é indicado por um partido ou um parlamentar em particular, a divulgação institucional ganha relevo e consistência, além de se livrar de cores e nuances ideológicas. Além disso, a cobertura diária fica diferenciada do trabalho de assessoria de imprensa do gabinete parlamentar.

Entretanto, como já se mencionou, a profissionalização da cobertura feita pelas mídias

\footnotetext{
${ }^{8}$ Apesar do potencial democrático, contudo, outras análises já apontam as dificuldades institucionais para realização da comunicação pública nos veículos legislativos, tais como o modelo de gestão e o perfil da programação (JARDIM, 2006).
} 
legislativas pode aproximá-las do padrão do jornalismo comercial praticado no País. Cabe ainda ressaltar uma questão que preocupa alguns profissionais: a cobertura jornalística das atividades da Câmara é a forma mais adequada de realizar a comunicação do Parlamento com a sociedade? Ou seriam necessárias outras ações para que os veículos legislativos conseguissem cumprir sua função constitucional da dar visibilidade ao Legislativo?

As respostas para essas perguntas não parecem estar claras entre os integrantes da burocracia de divulgação. Ainda existem discordâncias entre os profissionais que participam da atividade, embora o discurso dos gestores seja mais unificado em torno da pretensão de se aproximar do conceito de comunicação pública, com importância central para a credibilidade do sistema. Trata-se de algo que nem sempre é comprovado pela prática institucional dos veículos, utilizados para comunicar conteúdos informativos que não poderiam ser facilmente enquadrados como resultado de atividade jornalística.

Percebe-se que o discurso que sustenta a defesa institucional dos veículos legislativos utiliza o princípio constitucional da publicidade e também a contraposição à mídia comercial como forma de ampliar e melhorar a imagem pública do Parlamento. De certa forma, a ação dos produtores é uma estratégia política que busca a legitimação de novas práticas comunicacionais que se realizam nas mídias legislativas, especialmente em relação aos próprios cânones do jornalismo, calcado no modelo comercial da imprensa liberal no Brasil. Ao defender o direito dos cidadãos às informações sobre o Parlamento e ao criticar a imprensa comercial por não fornecê-las, os profissionais da Câmara estão afirmando o seu compromisso com a informação, apesar de atuarem em mídias institucionais. Ocorre que tais veículos não dispõem da autonomia administrativa e financeira que, em princípio, garantiriam a credibilidade das informações prestadas ${ }^{9}$. Como já foi enfatizado, todos eles, como parte da Secretaria de Comunicação Social, são submetidos diretamente às ordens da Presidência da Casa.

\section{Conclusão}

A definição sistemática de um discurso explicativo sobre o aparato burocrático de divulgação da Câmara dos Deputados não é tarefa simples. Em linhas gerais, o discurso fundador é centrado na difusão de informações jornalísticas, ou seja, o modelo que impera no setor privado. Essas mídias, portanto, atuam principalmente como centros burocráticos distribuidores de conteúdos, cujo diferencial é o enquadramento noticioso e a seleção de informações sob um prisma favorável ao Poder Legislativo. Com isso pretende-se mudar a reputação institucional, aumentar a visibilidade das abordagens positivas e conferir publicidade a aspectos negligenciados pela mídia comercial. Assim, o sistema de comunicação da Câmara se

\footnotetext{
${ }^{9}$ Obviamente, essa autonomia deve ser entendida dentro do quadro conceitual do jornalismo em seu modelo liberal, que necessita da publicidade comercial para garantir a autonomia da publicação. Como mencionamos acima, nem sempre isso ocorre na prática das atuais sociedades capitalistas.
} 
apresenta como contraponto à cobertura da mídia privada, como se a oferta de informação com angulação institucional fosse suficiente para produzir efeitos decisivos na opinião pública, legitimar a atuação desse sistema perante a sociedade e alterar o cenário político. Atualmente, esse sistema também se coaduna com a diretriz de transparência da Câmara, principalmente após a entrada em vigor da Lei de Acesso à Informação, no final do primeiro semestre de 2012.

Ao priorizar a difusão de conteúdos, as mídias legislativas reproduzem formatos, linguagens, cultura profissional, rotinas e dinâmicas produtivas dos veículos comerciais. Um exemplo é a ênfase na produção de conteúdos jornalísticos em todas as mídias do sistema TV, Rádio, Jornal, Agência de Notícias, provavelmente uma estratégia de uso da credibilidade do jornalismo como sistema perito para aumentar a confiança no Parlamento (BERNARDES E BARROS, 2010). Tal estratégia, como já foi mencionado, de fato fez com que da imagem de “chapa-branca" para a mídia externa, os veículos da Casa passassem a ser fonte primária de notícias. Esse foco informativo diminui as oportunidades de investir em práticas inovadoras de comunicação para estimular o debate público, a participação social e a interatividade com os públicos.

Por outro lado, por demandarem novos processos de produção e divulgação de informações, reconhece-se que as mídias legislativas são difíceis de serem avaliadas, visto que não se enquadram em categorias analíticas específicas pré-definidas e desafiam, em alguns pontos, as lógicas convencionais de produção e divulgação de informações. Um ponto óbvio, comum a todos os veículos de comunicação do campo público, é a ausência de objetivos financeiros dessas mídias. Mas os aspectos que diferenciam os veículos legislativos ultrapassam a questão comercial e deságuam não apenas na modificação das rotinas e dinâmicas produtivas, mas também no próprio discurso institucional dessas mídias. Analisar o discurso fundador, portanto, é um passo importante para desvendar esse novo campo de estudos e abrir possibilidades para investigações complementares sob a ótica da comunicação pública.

Durante o processo de consolidação dessas mídias, ao longo da última década, percebese que há redefinições, atualizações e mutações dos argumentos que embasam as práticas de divulgação. Não é objetivo deste trabalho analisar tal processo histórico ou as divergências entre os discursos dos profissionais sobre a prática comunicativa da Câmara, mas é preciso ressaltar que elas existem e vão desde a defesa de uma comunicação essencialmente política até a consideração e desejo de implantar práticas de comunicação pública nos veículos, de forma mais racional e com maior transparência social.

Em suma, é imprescindível reiterar que não há intenção de esgotar as questões suscitadas por essa nova prática comunicacional do Parlamento. Contudo, é importante destacar que as mídias legislativas demonstram algumas das mudanças em curso no Brasil. Ademais, tais veículos de informação constituem locus privilegiado para a observação das relações entre mídia e política, algo que não se pode desprezar no atual contexto político e sua interface 
sociomidiática.

Se antes mídia e política funcionavam em campos diferentes e próprios, a mídia legislativa traz o campo midiático para o ventre da política, reconfigurando tal relação. Se a mídia externa atua como instituição política concorrente, a legislativa passa a ser entendida como parte da estrutura política. A concorrência passa a existir em outros planos, como se explicou no decorrer do artigo: na tensão entre o uso político — próximo das relações públicas ou do marketing - e o uso para simplesmente ampliar a oferta de informações sobre o Legislativo, com vistas à cidadania.

\section{Referências}

ADGHIRNI, Zélia Leal. Sistemas de comunicação nos Três Poderes: quando o Estado se apropria do jornalismo para influenciar o espaço público. VIII Colóquio Brasil-França de Ciências da Comunicação. Anais ... Echirolles, França, 2006.

ALDÉ, Alessandra. A construção da política: democracia, cidadania e meios de comunicação de massa. Rio de Janeiro: FGV, 2004.

BARROS, A. T. de; BERNARDES, C. B. Comunicação pública na Câmara dos Deputados: a divulgação de informações legislativas no Brasil. In: PAULINO, F. de O. (Org.) Lusocomum: transparência, governança, accountability e comunicação pública. Brasília: Casa das Musas, 2009, p. 177-194.

BARROS, A. T. ; BERNARDES, C. B. ; LIMA, M. E. O. As emissoras legislativas e seus gêneros de programação. XVI Colóquio Internacional sobre a Escola de Comunicação LatinoAmericana. Anais... São Paulo, 2010.

BERNARDES, Cristiane Brum. O conceito de jornalismo público nos veículos da Câmara dos Deputados. Revista PJ:Br, São Paulo, v. 5, n.10, 2008. Disponível em: http://www2.eca.usp.br/pjbr/arquivos/ensaios10_c.htm Consultado em 05/08/14.

BERNARDES, Cristiane Brum; BARROS, Antonio Teixeira de. Jornalismo no Parlamento Brasileiro: Sistema perito para ampliar a confiança na democracia? In: IV Jornadas Internacionais de Jornalismo, 2009, Porto. Actas das IV Jornadas Internacionais de Jornalismo. Porto: Edições Universidade Fernando Pessoa, 2009, p.303-332.

BERNARDES, C.B.; BARROS, A. T. de. A credibilidade jornalística como instrumento para ampliação da confiança no Parlamento. In: MESSENBERG, D. et al (Org). Estudos Legislativos: 20 anos da Constituição brasileira. Brasília: Senado Federal, 2010, p.164-192.

BEETHAM, David. Freedom as the foundation. In: DIAMOND, Larry; MORLINO, Leonardo (Ed.) Assessing the quality of democracy. Baltimore: Johns Hopkins University Press, 2005.

BERNARDES, Cristiane Brum. Parlamentares $\times$ jornalistas: a dinâmica política das mídias legislativas da Câmara dos Deputados. Sociedade e Estado. Brasília , v. 28, n. 3, Dez. 2013, p.663-689 .

BOBBIO, Norberto. Estado, governo, sociedade: para uma teoria geral da política. $12^{\mathrm{a}} \mathrm{ed}$. Rio de Janeiro: Paz e Terra, 2005.

BOURDIEU, Pierre. O poder simbólico. Rio de Janeiro: Bertrand Brasil, 2006.

CHARAUDEAU, Patrick. Discurso das mídias. São Paulo: Contexto, 2006.

DAHL, Robert. Democracy and Its Critics. New Haven: Yale University Press, 1989.

DURKHEIM, Émile. Lições de Sociologia. São Paulo: Martins Fontes, 2002. 
COOK, Timothy. Making laws and making news: Media strategies in the U.S. House of Representatives. Washington: The Brookings Institution, 1998.

ENTMAN, Robert M. Democracy without citizens: Media and the decay of American politics. New York: Oxford University Press, 1989.

FERRY, Jean-Marc. Prefácio. In: LIBOIS, Boris. La communication publique: por une philosophie politique des medias, p. 5-8. Paris: L'Harmattan, 2002.

GOLDENBERG, Mirian. A arte de pesquisar: como fazer pesquisa qualitativa em Ciências Sociais. Rio de Janeiro: Record, 2001.

GUIZOT, François. A história das origens do governo representativo na Europa. Rio de Janeiro: Topbooks, 2008.

KARVAT, Erivan C. A historiografia como discurso fundador: reflexões em torno de um programa histórico. Revista de História Regional, Ponta Grossa, 10, 2: 47-70, 2005.

LIBOIS, Boris. La communication publique. Paris: L'Harmattan, 2002.

LIMA, Venício. Mídia: teoria e política. São Paulo: Fundação Perseu Abramo, 2001.

MALAVAZI, Ademir. Manual de Redação da Secom. Brasília, Câmara dos Deputados, 2004.

MIGUEL, Luis Felipe. A mídia e o declínio da confiança na política. Sociologias, Porto Alegre, s.v., n. 19, Jun., 2008, p. 250-273.

MOISÉS, José Álvaro. Democracia e confiança: por que os cidadãos desconfiam das instituições públicas? São Paulo: Edusp, 2010.

ORLANDI, Eni. Discurso fundador: a formação do país e a identidade nacional. Campinas: Pontes. 2001.

. Análise de discurso: princípios e procedimentos. Campinas: Pontes, 2007.

PIMENTEL, Fábio Prado. O rádio educativo no Brasil: uma visão histórica. Rio de Janeiro: Soarmec Editora, 2004. Disponível em

http://www.radioeducativo.org.br/800/..\%5Cartigos\%5Clivrofinal2.pdf. Consultado em $02 / 05 / 2014$.

RENAULT, Letícia. Comunicação e política nos canais de televisão do Poder Legislativo no Brasil. Belo Horizonte: Assembleia Legislativa do Estado de Minas Gerais, 2004.

RODRIGUES, Malena Rehbein. O papel da imprensa na qualidade democrática - uma análise de possibilidades nos principais jornais nacionais. Tese (Doutorado em Ciência Política). IESP/UERJ/Cefor, Brasília, 2011.

RUBIM, Antônio Albino Canelas. Mídia e política: transmissão de poder. In MATOS, Heloiza (Org.) Mídia, eleições e democracia. São Paulo: Página Aberta, 1994.

SANTOS, Paulo César Pereira dos. A crise de representatividade do legislativo e a mídia: os princípios norteadores da implantação do sistema de comunicação institucional da Câmara. Trabalho de conclusão (Curso de Aperfeiçoamento em Mídia e Política). Instituto de Ciência Política, Universidade de Brasília, Brasília, 2005.

SARTORI, Giovanni. Homo videns. Bauru Edusc, 2001.

THOMPSON, John B. Ideologia e cultura moderna: teoria social crítica na era dos meios de comunicação de massa. Petrópolis: Vozes, 1995.

WEBER, Max. Economia e Sociedade. Brasília: Editora da UnB, 1999.

Artigo recebido em: 04/06/2014

Artigo aceito para publicação em: 11/08/2014 